B) Observatori de

Bioètica i Dret

ISSN: $1886-5887$

\section{Revista de Bioética y Derecho}

Publicación del Máster en Bioética y Derecho nww.bioeticayderecho.ub.edu

ARTíCUlo

\title{
Distinguish Patients in a Vegetative State from the Minimally Conscious state: moral and legal dilemmas
}

SILVIA ZULLO*

* Silvia Zullo. Research Fellow in Bioethics at CIRSFID - School of Law of the University of Bologna. silvia.zullo@unibo.it

Esta es una revista de acceso abierto, lo que significa que todo el contenido es de libre acceso sin costo alguno para el usuario o su institución. Los usuarios pueden leer, descargar, copiar, distribuir, imprimir, buscar, o enlazar los textos completos de los artículos en esta revista sin pedir permiso previo del editor o del 


\title{
Index
}

1. Introduction

2. New Neuroscientific findings and Old Moral-Legal Dilemmas

3. Best Interest and the Right to Self-Determination in the Decision of Discontinuing Life Support

3.1 The "Italian Case" in the Contemporary Debate

4. Recent neuroimaging tests: what shall we do?

5. Conclusions

\begin{abstract}
Research done using current neuroimaging techniques-specifically, positron emission tomography (PET) and functional magnetic resonance imaging (functional MRI)—have provided evidence that vegetative patients may have fragments of consciousness. These findings make all the more urgent the familiar moral and legal dilemmas arising in connection with persons in these "reduced" states, because in debating whether these persons have a will, we have to take into account the possibility that they may have "glimpses of consciousness". In other words, we have to revisit that principle in light of scientific advances enabling us to more accurately detect signs that a patient is expressing a will to be taken off life support.
\end{abstract}

Key words: vegetative state, minimally conscious state, right to self-determination, best interest, neuroimaging. 


\section{Introduction}

Current neuroimaging techniques -PET and functional MRI-have encouraged neurologists to have a closer look at vegetative patients' clinical condition, exploring their residual cognitive abilities and their degree of awareness following serious brain injury. A recent example is Monti et al. (2010), who have attracted the attention of the scientific community for the findings they have reported in a study in which they asked questions to vegetative and minimally conscious patients and observed how the brain responds in these subjects in comparison with the brain response of conscious subjects: 5 responses were detected over a total of 54 subjects enrolled in the study, and in one case the response suggested a state of consciousness. Research in deep brain stimulation has shown that in some vegetative patients some areas of the brain remain active, making it possible to give voluntary behavioral responses to such stimulation, and in this way we can detect in these patients a transition from the vegetative state to the minimally conscious state. 1

These diagnostic findings and advancements in neurology are compelling us to rethink the way we do diagnosis and prognosis for patients in a vegetative state (VS) or in a minimally conscious state (MCS), making it even more urgent to find a shared moral and legal basis on which to decide what treatments these patiens should undergo, especially as concerns the decision to end or prolong life support.

As is known, patients in a vegetative state present a peculiar clinical picture: we are dealing with persons who have come out of a coma and yet cannot seem to make any contact with their surroundings. And this impossibility, or at least the difficulty these persons have in establishing any such form of communication, makes it quite hard to determine how conscious they are of themselves and of the outside world: a state of consciousness does persist in these patients, but the standard clinical tests used to detect it do not take the peculiarity of this state into account, thus making such detection all the more difficult. This is a serious failing, considering that some "vegetative patients" do, after a time, give signs of recovery, appearing to resume contact with the environment and move into a "new" permanent clinical condition, namely, the minimally conscious state. As much as these signs may be intermittent and are not a sufficient basis on which to find that these patients are conscious of themselves or of their surroundings, they nonetheless have made it possible to distinguish the vegetative state from the minimally conscious state and to identify some previous diagnoses as incorrect.

These findings make all the more urgent the familiar moral and legal dilemmas arising in connection with persons in these "reduced" states, because in debating whether these persons have a will, we have to take into account the possibility that they may have "glimpses of consciousness," and

1 It remains difficult to diagnose the MCS in clinical practice because the state is, after all, transitional, and so, while it may signal a trend, showing that the patient is regaining consciousness, it may just as likely settle into a permanent state of minimal consciousness. See Giacino et al. 1997. 
this will make increasingly problematic the idea that we should always apply by default the principle In dubio pro vita in deciding whether to discontinue or prolong life support.

\section{New Neuroscientific findings and Old Moral-Legal Dilemmas}

As is known, the VS condition cannot be classed as a "natural" end-of-life stage, for it is a new way of dying closely tied to recent biomedical advances. In addition, its diagnosis is probabilistic, nor is its prognosis any more certain. In 1972, Jennett and Plum observed a new clinical condition they described as neither a state of unconsciousness nor a coma in the ordinary sense of the term, but a state of wakefulness without consciousness (Jennett and Plum 1972). But this characterization of the VS has since been revised with the introduction of neuroimaging techniques, which have given us new findings that further complicate both diagnosis and prognosis for such patients. Further complicating the scene is the MCS that has since been described (Giacino et al. 2002), where vegetative patients who have suffered brain injury in time give signs suggesting that they are reestablishing contact with their environment (Defanti 2007).

As problematic as a prognosis of irreversibility is (for obvious moral reasons), even more complicated and difficult is a prognosis for the MCS, where the patient can satisfy simple requests and show intentional behavior (such as following an object with the eyes). As early as the late 1990s, the frequent misdiagnoses of the past prompted the scientific community (a group made up not only of neurologists but also of psychologists and philosophers) to call for more research into the way the VS is diagnosed: they were aiming to find a scientific basis on which to determine whether or not these patients still had a functional mind, and one concern they had was to ensure as far as possible that moral prescriptions and legal solutions could be framed without any ideological capture, which very much seems to be the trend now in the bioethical and legal debate, with the increasing tendency to envelop empirical data in value judgments.

And a further aim was to offer guidance to neurologists in diagnostic and therapeutic decisionmaking and supporting family members in deciding on a therapeutic course, in that a reliable diagnostic and prognostic basis can go a long way toward helping us make thoughtful decisions for ourselves and for others.

We are not yet in a position to tell whether the stimulus-and-response brain activity that can be detected using functional MRI with vegetative patients can be taken as evidence of anything more than a state of wakefulness. However, a 2006 study led by S. Laureys in Liège and A. M. Owen in Cambridge attracted a great deal of interest in the scientific community for its diagnostic use of this neuroimaging technology. The study (Owen et al. 2006) is similar to the one previously discussed (Monti et al. 2010, in which Owen also took part), in that the basic idea, here too, was to assign the same task to subjects in two different groups (healthy subjects, on the one hand; a vegetative patient, on the other) and use functional MRI to compare their brain activity. The task in this case was to imagine yourself playing tennis and then walking around your own home (30 seconds of sustained 
brain activity for each request): Owen observed that the vegetative patient (she had been in that condition for five months after traumatic brain injury) responded to the instructions through a cortical activation pattern similar to that of the volunteers in the healthy group: he drew the conclusion that she not only understood but also acted to carry out the instructions, and that this was evidence of an intention on her part. In the corroborating study of 2010, which Owen conducted with M. M. Monti in Oxford and Cambridge (Monti et al. 2010), 23 subjects involved were VS patients and 31 were MCS patients, and of the 5 corroborating responses-similar to the one observed in the vegetative patient in Owen et al. 2006-2 were in the VS group and 3 in the MCS group.2

To be sure, it is still too early to extract any definite normative conclusions from these findings, but in view of the rapid pace at which these functional imaging technologies are developing, we can see a future in which empirical findings will offer valuable support in making end-of-life decisions for and with patients in conditions we won't be able to treat-patients we consequently won't be able to bring back to a state of consciousness.

The most controversial of the questions to which the neurotechnologies are imparting a new sense of urgency are those involving the moral status of persons in a VS-at once patients and "moral agents"-and the way the law ought to regulate end-of-life decisions in these cases. Neuroimaging, in other words, is compelling us to think ever more carefully about the moral obligations we as a society have to persons in a VS or an MCS, and about the rights they ought to be recognized as having.

\section{Best Interest and the Right to Self-Determination in the Decision of Discontinuing Life Support}

The first case where a judge ruled in favour of discontinuing life support for a vegetative patient who had previously expressed a wish not be artificially kept alive in that condition, should it so happen, was in Massachusetts in 1986 (Paul Brophy), when it was decided to discontinue artificial provision of nutrition and hydration (ANH). And in 1991 (in the Helga Wanglie case) physicians and family members were arrayed on opposite sides, the former arguing against life support and the latter in favour, and the court came down on the side of the family, recognizing the woman's husband as her rightful guardian, thus empowering him to make medical decisions in her best interest (Angell 1991).3

2 Another corroborating study-also with Owen, who again worked with Laureys, of the University of Western Ontario-is Cruse et al. 2011, in which traces of intentional behaviour were detected at the bedside in the brains of patients who had been misdiagnosed in a VS, precisely because their outward behaviour did not suggest any intentionality. What is new and exciting about this study is that it relied on electroencephalography (EEG), a technology more accessible than functional MRI, and since the study shows that EEG can be used for bedside detection of awareness, it also shows the prospect of bringing this technology to the home.

3 For a clinical viewpoint on the controversial question of whether to discontinue life-sustaining treatments, see the document the bioethics and palliative care research group of the Italian Society of Neurology put out in 2002. The document was recently republished: see Gruppo di studio 2010. 
Now accepted across much of the United States is the substituted judgment doctrine for deciding whether to withhold or maintain life-sustaining treatments for persons who did not clearly state their wishes before lapsing into a vegetative state: under this standard, a surrogate decision maker will try to make a decision based not so much on the patient's best interest as on the patient's own values and frame of reference, by taking into account any views the patient may have expressed as a healthy person about similar treatments and cases, as well as the patient's moral, philosophical, or religious beliefs and outlook, so far as these can be reconstructed through a close acquaintance with the patient. From a clinical point of view, the American Academy of Neurology reaffirmed in 2006 the position statement it had first issued in 1988, saying that ANH may be discontinued so long as it can clearly be established that the patient would not have wanted any further medical treatment and the family agrees with that decision. 4

An emblematic case as concerns disagreement over whether to withdraw ANH is that of Terri Schiavo, for it brings into focus how the parties with a rightful claim to make decisions on the patient's behalf (here parents and spouse) can have contrasting views about what is in the patient's best interest. This turned out to be a dramatic case in both a moral and a legal sense, resulting in a legal battle and in the Florida state legislature passing what came to be known as "Terri's Law" (2003), under which the governor was authorized to issue a one-time stay preventing Terri's husband and guardian from carrying out a Florida court order to discontinue the ANH administered to keep Terri alive. This law was passed despite a previous 1997 law in Florida under which someone acting as guardian for a patient on life support can have that treatment discontinued even without a living will showing that to be the patient's intention.5 Terri's law was later struck down (by the Florida Supreme Court in 2004), and the decision was then appealed several times in the federal court system without success.

These and other cases highlight the complex ethico-legal quandaries of public policy that come into play in asserting a vegetative patient's right to self-determination absent any clear and convincing evidence on which basis to determine whether or not the patient would have wanted to be kept on life support. At stake is the process toward a subjective criterion for making decisions about the body and about end-of-life care, a criterion that comes under even greater moral and legal strain where patients are incapacitated to either make or express a meaningful decision in that regard. Three are the basic moral arguments offered in favour of continuing life support in cases where the patient has not expressed any wishes: the argument of the intrinsic value of human life, the argument that withdrawing life support would amount to violating the patient's moral autonomy, and the risk of misdiagnosis. What all these arguments have in common is that they must all grapple at some level

4 So the American Academy of Neurology is not saying that life-sustaining treatment is to be withheld in all cases involving a patient in a VS, for that would violate any advance decision the patient may have made to prolong such treatment (see American Academy of Neurology 1989).

5 Under Florida law, a request to discontinue life-sustaining treatment may be granted only on either of two conditions: either "clear and convincing evidence" is offered that this is what the patient would have chosen to do, or the decision can be shown to be in the patient's best interest. 
with the problem of recognizing vegetative patients as having a right to self-determination in making choices about their own body. This, in other words, is the problem of recognizing the subjective point of view, and the accompanying problem of showing this to be a legitimate and compelling point of view, not only in a moral sense but also in a legal one. Which in turn brings up the problem of how to determine and decide whether the patient has an interest in being kept alive, and so whether the state should always act to protect the patient's life as a matter of public policy.

In the Tony Bland case in Great Britain (1993), the House of Lords ruled that once it is determined that a vegetative patient has no chance of recovery, it is legitimate to take that patient off life support even without any prior indication on the patient's part as to how he or she would have wanted to be treated in such a condition. This decision was made relying on the criterion of what is in the patient's best interest, a standard framed in medical terms. In this sense, the decision in the Bland case can be analogized to that made by the US Supreme Court in the earlier case of Nancy Cruzan (1990), for in this case, too, there was no advance refusal of treatment, and like the House of Lords, the US Supreme Court recognized a patient's right to refuse medical treatment even when it could prolong the patient's life. However, the basis for this decision was altogether different than in the Bland case, in that Cruzan was not decided on the basis of what was in the patient's best interest: it was instead heard as a due process case, making the controlling criterion that of the patient's wishes and right to self-determination, for which reason the court also held that close family members seeking to withdraw life support must produce "clear and convincing evidence" to that effect before their "substituted judgment" may be acted on. This is not to say, however, that these two standards are mutually exclusive: they may very well both figure into a decision, and so the question becomes one of balancing, that is, how can we balance what is good for the patient in a medico-scientific sense with what is good according to the patient's own view? Which, in other words, is the question of how to balance the "objective" point of view with the subjective one (cf. D'Aloia 2010).

\subsection{The "Italian Case" in the Contemporary Debate}

The most famous and complex case to have come out of Italy over the last two decades is that of Eluana Englaro (2009), which in several respects can be analogized to the American cases, and in particular to Cruzan.6 One sense in which we can see this is by looking at Section 7.5 of the ruling the Italian Supreme Court of Cassation issued in 2007 regarding the Englaro case, laying emphasis on the need to reconstruct the patient's own outlook on life:

6 Two other landmark cases in the United States, besides Cruzan (1990), are the previously discussed Schiavo case (2005) and the Quinlan case (1976). Here the New Jersey Supreme Court ruled that once it is ascertained that a patient has no chance of recovering from a PVS, family members may assert the patient's right to privacy and decide on that basis whether or not to continue life-sustaining treatment. 
[...] if it can be determined what an unconscious patient's will would be-through a reconstruction based on clear, unambiguous, and convincing evidence, taking into account not only the wishes the person concerned actually articulated before becoming incapacitated, but also the person's way of life, sense of integrity, and core interests and experiences-we can make sure that the choice made on that basis neither reflects the guardian's assessment of the patient's quality of life (however much that guardian may be a close family member) nor is precipitated by the gravity of the situation, but is instead exclusively aimed at providing the substance on which basis to frame a coherent picture of the patient's overall identity and of the way the patient would conceive the very idea of the dignity of the person had he or she not lapsed into an unconscious state.7

Another similarity between the Cruzan and the Englaro cases is that family members in either case were ultimately allowed to decide for the patient not as family members but as legal guardians, for the point is to reconstruct what the patient would have wanted, rather than the will of those who substitute for the patient in making a judgment. Or, stated otherwise, those who substitute for the patient in this decision-making capacity are supposed to do so not as family members but as "spokespersons," that is, as persons who can faithfully and accurately convey any wishes the patient had clearly expressed before becoming incapacitated, or who, absent such a clear advance statement of intent, can reconstruct the person as closely and faithfully as possible and make a corresponding judgment. The Englaro ruling can in this sense be said to have taken up the substituted judgment criterion, in an effort to locate as far as possible in the patient, rather than in the doctor, the moral authority to make end-of-life decisions regarding the patients themselves. For which reason the ruling clearly states that the legal guardian is bound to decide neither in lieu of the patient nor for the patient but with the patient, precisely in order to respect the patient's will as a moral decision-maker.

The moral complexity these cases present lies in the problem of the kinds of reasons one can give in justifying a decision to withdraw treatment: such a decision may be based on hard facts, once it is determined that any further treatment would not improve the patient's condition, but this determination alone-what one may call the objective basis of judgment-cannot properly justify the decision, which needs to be based on moral grounds, and this is where the subjective basis of judgment comes into play, for if we are to proceed in keeping with the patient's right to selfdetermination, we should try as far as possible to reason from the standpoint of the patient's own subjectivity, taking into account not the way we perceive the patient's condition but the way the patient would perceive it.

The Englaro case underscores how the courts in Italy, like those in Europe and the United States, are often asked to decide on these cases before there is any specific legislation on the books regulating the subject matter. However, absent a legislative corpus, the judges can look to constitutional principles and international law, and from this emerges an ethico-legal framework serving as a decision-making guide. 8

7 Cassazione 2007, 83; my translation.

8 On the question of finding appropriate judicial solutions in a context where codified law has yet to catch up in 
By the same token, every advancement in science and technology forces us to rethink the vegetative state in such a way as to require the support of a normative framework extending beyond national boundaries. In Europe, the relevant principles are set forth in the Nice Charter and the Oviedo Convention, 9 which practitioners, ethics committees, and professional associations then translate into guidelines serving not only as a practical model for those in the field, but also as a source of guidance for those outside the profession, or indeed for anyone who may find themselves having to decide for someone close to them, or who may want to decide in advance for themselves in cases where they should become incapacitated, lapsing into a state where they can no longer express that decision or exercise their decision-making autonomy.

The current bioethical and legal debate is focused precisely on this last point, namely, our right and freedom to each choose a course of action for ourselves before our own life should turn into something where a legitimate question may arise as to its inherent worth. And since the Italian Constitutional Court has found that the principle of informed consent brings together the two basic personal rights to self-determination and to health,"10 it stands to reason that informed consent should apply to all choices we can make relative to the body, including choices concerning life-saving treatments.

This idea of self-determination embedded in the principle of informed consent suggests that we have to take a harder look at those cases in which patients have not stated in advance how they would want to be treated. And Brock (2001, 232-41; cf. Brock and Buchanan 1989) suggests here that we should be less concerned with the abstract question of the status of life-sustaining treatmentwhether it is ordinary ("natural") or extraordinary-and more concerned with the practical question of whether and to what extent such treatment can actually benefit a patient in each specific case. 11

So the sticking point of the debate is whether patients have a right to refuse life-sustaining treatment. And the question proves especially difficult or intractable in cases where we have no clear advance statement by the patient. One way to solve the problem is do decide on the basis of the patient's best interest. But this is a medical criterion, and as such it fails to see the problem from the

the matter of end-of-life decision-making, see Tripodina (2004, 220-56). Cf. D'Aloia 2010 and Veronesi 2007. 9 The full titles are The Charter of Fundamental Rights of the European Union (2000) and Convention for the Protection of Human Rights and Dignity of the Human Being with regard to the Application of Biology and Medicine: Convention on Human Rights and Biomedicine (1997).

10 "That the basis for informed consent lies in Articles 2, 13, and 32 of the Italian Constitution underscores the function of informed consent in synthesizing the two basic personal rights: that to self-determination and that to health" (Corte Costituzionale 2008, quoted in Corte Costituzionale 2009).

11 As was previously noted, the former question is ethically and scientifically controversial. A policy statement the Italian National Bioethics Committee issued in 2005 on artificial nutrition and hydration (Comitato 2005; cf. Comitato 2003) drew much criticism in Italy and was quickly amended with an addendum making explicit the internal dissensions of the committee itself, which had taken the view that this is an ordinary sort of treatment and that the physician is thus bound to administer it, in contrast to the international scientific consensus that ANH can be discontinued just like any other medical treatment, regardless of whether it is to be considered ordinary or extraordinary. 
standpoint of the patient understood as a moral agent, that is, as someone capable of making choices based on some sort of conception of what is good, valuable, or worthy in life. And that suggests a second criterion, one that recognizes a patient's right to self-determination, and it is this second criterion that appears to be gaining ground as the moral and legal consensus: its weakness lies not so much in its moral basis as in its technical implementation, for we can never really know what a vegetative patient would want; we can at best reconstruct what we believe to be his or her will. The two criteria can in this sense be said to stand in an inverse relation to each other: whereas the best interest criterion is strong on technical grounds but weak on moral ones, what we might call the selfdetermination criterion stands on solid moral grounds but is technically weak because it must settle for what the patient presumptively would want.12

\section{Recent neuroimaging tests: what shall we do ?}

The crucial point, when it comes to framing public policies and legal principles on which basis to treat patients in a vegetative or minimally conscious state, is the question of so-called surviving interests, meaning those interests which survive one's capacity as a fully endowed moral agent, and which can accordingly be ascribed to an agent no longer capable of exercising that former capacity or of conveying a moral choice. The question is crucial and difficult precisely because, as was mentioned at the end of the last section, there is no guarantee that we can accurately determine the patient's will, either because we do not have a clear antecedent statement from the patient or because, even if we did have such a statement, we would have no way to make sure that this is what the patient would want today, were he or she able to convey thoughts to us (that is, there would be no way for us to make certain that the patient has not had a change of heart), with the consequence that we can only go on what we presume to be the patient's will and outlook. This is a difficulty we will have to overcome if we are to recognize an incapacitated patient as having the same (surviving) interests as his or her formerly fully capable self, and one way to support this thesis is to argue that if both selves can be recognized as moral agents, they stand on an equal moral footing, such that, on a principle of equality, we ought to recognize the same interests for one that we do for the other. This is not to say that we can protect those interests-because a positively accurate understanding of them can only come from the patient, and so we can at best rely on a presumptive reading of those interests if the patient cannot communicate-but still, what we might call here the surviving-interests approach comes closer to protecting a patient's right to self-determination than does the rival approach, which by contrast seeks to protect the patient's best interests by working on an assumption that life is to be preserved at any cost, even if this contradicts what the patient would want. It is for this reason that I argue for a social contract based on the primacy of the patient's dignity and will as a moral agent entitled to choose whether to suspend or prolong life-sustaining treatments.

12 A discussion of the ethico-legal questions involving vegetative patients can be found in Galletti and Zullo 2008. See also Neri 2011, 1796-97. 
A 2005 survey conducted in the United States in the wake of the Terri Schiavo case found that only $8 \%$ of Americans would want to be kept alive in a vegetative or minimally conscious state; $87 \%$ said they would not want life-sustaining treatment, suggesting that most people find more worrisome the prospect of being kept indefinitely alive in a merely biological condition than the prospect of dying (Constable 2012). It is thus not a foregone conclusion that the best interest of a patient in a VS always consists in doing whatever is possible to keep the patient alive, for this person may well be of a mind to reject this kind of treatment, such that his or her best interest may in fact be served by discontinuing the same treatment.

One argument frequently invoked in favour of prolonging life-sustaining treatment consists in pointing out that discontinuing such treatment would effectively wipe out any glimmer of hope there may be that the patient might recover some fragments of consciousness. However, this argument depends on the ability to correctly diagnose and distinguish between the VS and the MCS. This not an easy task, and the rare instances of coma survivors involve the mistake of diagnosing as a VS what is actually an MCS. Recent neuroimaging tests and techniques offer data that can help make diagnosis more accurate by making it possible to identify degrees of consciousness, though it must be said that a VS can never be diagnosed with full certainty: the best that can be done is to work out the probability that someone is in a VS.

On the other hand, the greater diagnostic accuracy made possible by neuroimaging, giving us useful data on which to base our judgment about a vegetative patient's state of consciousness, can be used in combination with advance health-care directives as tools based on a principle of informed consent. Which is to say that the information individuals are provided when they fill out an advance directive can be made to include a description of what exactly is meant by a VS and an MCS, how a diagnosis is reached in each case, and what the likely prognosis would be-all information that can guide one in making care decisions regarding the future.

There is another way in which functional MRI can be a useful tool in dealing with the morally and legally fraught issue of whether it may be legitimate and even appropriate to discontinue lifesustaining treatment, in that, by making it possible to identify fragments of cognitive activity, giving one reason to hope that the patient can recover some cognitive function, this technology could be used to enable some forms of communication between patients and family members (see Coleman et al. 2007).

On the other hand, we should also consider that no data is yet available on vegetative patients who have been so diagnosed by functional MRI. And it must further be considered that a state of minimal consciousness may not be beneficial to the patient: it may turn out to be a terrible condition of stabilized semi-awareness coupled with an existence in an incapacitated body. What we have to understand is whether we can look to scientific certainties about these conditions in the future as the biotechnologies progress, and how such certainties will affect the way we think about these problems: there is no doubt, on a precautionary principle, that vegetative patients whose wishes are unclear need to be kept alive if there is even the slightest doubt that they will regain consciousness, but in the future will have to give greater scope to the principle of informed consent. Indeed, the better we become at detecting degrees of consciousness (through the use of increasingly sophisticated 
diagnostic tools), the more we can put individuals in a position enabling them to make thought-out, informed choices about life-sustaining treatments; and, by the same token, we can stop discriminating between these patients, who can make a choice, and those who cannot or are thought to be unable to, and who may be forced to undergo treatments they have not requested and may not want.

Right now neuroimaging can be used to determine whether a vegetative patient is actually in an MCS. Patients in this latter condition can make decisions even with serious cognitive deficits, and it may be that they want to be helped to die, by requesting that life support be removed (Wilkinson et al., 2009). There is certainly an obligation to care for vegetative and minimally conscious patients and make sure they feel as little pain as possible, but it is open to question whether-lacking an indication as to how they would want to be treated-we are under a moral obligation to prolong their lives. These patients can only experience the present moment: they do not have any experience of the self over time and so cannot conceive of a life plan, because they cannot see themselves in the future. Of course it would be wrong to keep on life support a patient who has clearly expressed in advance a wish not to be kept alive in a VS: that much ought to be clear.13 It is only in cases where we cannot count on a patient's advance directive that the problem becomes morally difficult to work out, and it is in this grey area that I have been moving in this article, offering arguments as to why the best course of action may not always lie in prolonging life-sustaining treatment no matter what.

\section{Conclusions}

What I have sought to do in this discussion is to lay out two basic moral grounds on which to proceed in thinking about how to care for vegetative and minimally conscious patients: on the one hand we can proceed on the best-interest criterion and assume that life trumps all other interests; on the other hand we can proceed from a view of patients as moral agents entitled to decide for themselves. The problem with the first approach is that it is too often taken to entail a rejection of the second and winds up discriminating between patients who can exercise a right to refuse life-sustaining treatment and those who cannot. The problem, then, is how to make it possible for someone to exercise their rights to self-determination even after they have indefinitely lost their consciousness, or how to ensure a surviving interest for these patients, and the only tool we have so far evolved in solving this problem is that of the advance directive. However imperfect a tool this may be, it does not have the drawback of assuming that all patients are the same and should get the same treatment regardless of their specific condition and individuality.

13 On July 12, 2011, the lower house of Parliament in Italy passed what came to be known as the "Calabrò" bill on advance directives, now waiting for Senate approval to become law. There are many points of controversy in the language of this bill, but one issue that has proved to be especially contentious is that of artificial nutrition and hydration, since the bill provides for the possibility of requesting such treatment in an advance directive, but no possibility of refusing it. For a discussion of this bill and the debate it has sparked, see Dossier 2011. 
The moral complexities involved in the vegetative and minimally conscious states make it necessary to rethink the way we care for patients in these states. Indeed, since their condition is not amenable to medical treatment-at least not in the sense of restoring one to a state of wakeful thought and experience-we have to think outside the box of strict medical procedure, expanding our view so as to take in possibilities other than that of preserving life as a strictly biological construct. We have to at least balance a patient's right to life with his or her right to self-determination (the latter entitling the patient to refuse life-sustaining treatment, while obligating physicians to accordingly suspend such treatment when there is no reasonable chance of recovery). Indeed, both of these rights issue from a need to respect the dignity of the person, and there is no reason why the former right should take precedence over the latter as a matter of principle. Two essential tools if we are to give scope to these latter rights without sacrificing the former are the advance medical directive we have so far been discussing that the Patient Self-Determination Act (see Bradley 1998): both can be expected to play a larger and larger role over time as diagnostic techniques improve; both enable patients to exercise their rights as moral persons entitled to choose their own course of action; and both enable doctors to work with patients and family members in figuring out what that course should be. But there is still a lot to be done before we can say we have extended to incapacitated patients the same rights we now recognize for competent ones.

\section{References}

- American Academy of Neurology, 'Position of the Academy of Neurology on Certain Aspects of the Care and Management of the Persistent Vegetative State Patient', Neurology, 39 (1989), pp. 12526.

- M. Angell, 'The case of Belga Wanglie: A New Kind of "Right to Die" Case'. New England Journal of Medicine, 325 (1991), pp. 511-12.

- E.H. Bradley, 'The Patient Self-Determination Act and Advance Directive Completion in Nursing Homes', Archives of Family Medicine, 7 (1998), pp.417-23.

- D. Brock, Medical Decisions at the End of Life. In A Companion to Bioethics, ed. H. Kuhse and P. Singer. (Oxford, UK, Blackwell Publishing, 2001).

- D. Brock and A.E. Buchanan, Deciding for Others: The Ethics of Surrogate Decision Making, (Cambridge, UK: Cambridge University Press, 1989).

- Cassazione (2007) Oct. 16, no. 21748. Nuova Giurisprudenza Civile Commentata, 2008, I, 83.

- Comitato Nazionale per la bioetica (2003). Dichiarazioni anticipate di trattamento. http://www.governo.it/bioetica/pareri.html.

- Comitato Nazionale per la bioetica (2005). L'alimentazione e l'idratazione di pazienti in stato vegetativo persistente. $\mathrm{http}: / /$ www.governo.it/bioetica/pareri.html. 
- M.R. Coleman, J.M. Rodd, M.H. Davis, I.S. Johnsrude, D.K. Menon, J.D. Pickard and A.M. Owen, 'Do Vegetative Patients Retain Aspects of Language Comprehension? Evidence from fMRI', Brain, 10 (2007), pp. 2494-2507.

- C. Constable, 'Withdrawal of Artificial Nutrition and Hydration for patients in a Permanent Vegetative State: Changing tack', Bioethics, 3 (2012), pp.157-63.

- Corte Costituzionale (2008), December 23, no. 438.

- Corte Costituzionale (2009), July 27, no. 253.

- Cruse D., Chennu S., Chatelle C., Bekinschtein T.A., Fernández-Espejo D., Pickard J.D., Laureys S, Owen A.M. (2011). Bedside Detection of Awareness in the Vegetative State: A Cohort Study. The Lancet, 378 (9809): 2088-2094.

- A. D’Aloia, 'Al limite della vita: Decidere sulle cure', Quaderni Costituzionali, 2 (2010), pp. 237-268.

- C.A. Defanti, Soglie: Medicina e fine vita (Turin, Bollati Boringhieri, 2007).

- Dossier, Bioetica: Rivista Interdisciplinare, 4 (2011), pp. 615-751.

- M. Galletti and S. Zullo S. eds., La vita prima della fine (Florence, FUP, 2008).

- Giacino J.T., Zasler N.D., Katz D., Kelly J.P., Rosenberg M.D., Filley C. (1997) Development of Practice Guidelines for Assessment and Management of the Vegetative and Minimally Conscious States. Journal of Head Trauma Rehabilitation 12 (4): 79-89.

- Giacino J.T., Ashwal S., Childs N., Cranford R., Jennett B., Katz D.I., Kelly J.P., Rosenberg J.H., Whyte J., Zafonte R.D., Zasler N.D. (2002). The Minimally Conscious State: Definition and Diagnostic Criteria. Neurology 58, no. 3: 349-53.

- Gruppo di studio di bioetica e cure palliative della società italiana di neurologia (2010). La sospensione delle misure di sostegno vitale nello stato vegetativo permanente: Vent'anni di riflessione bioetica in neurologia. Bioetica: Rivista interdisciplinare, 2: 123-43.

- B. Jennett and F. Plum, 'Persistent Vegetative State after Brain Damage: A Syndrome in Search of a Name', The Lancet 1 (1972), pp. 734-37.

- M.M. Monti, A. Vanhaudenhuyse, M.R. Coleman, M. Boly, J.D. Pickard, L. Tshibanda, A.M. Owen, S. Laureys, 'Willful Modulation of Brain Activity in Disorders of Consciousness', New England Journal of Medicine, 362 (2010), pp. 579-89.

- D.Neri, Il diritto di decidere la propria fine, In II governo del corpo, ed. S. Canestrari, G. Ferrando, C. Mazzoni, S. Rodotà, and P. Zatti. In vol. 2 of Trattato di biodiritto, ed. S. Rodotà and P. Zatti (Milan, Giuffré, 2011).

- A. M. Owen, M.R. Coleman, M. Boly, M.H.Davis, S. Laureys , J.D. Pickard, 'Detecting Awareness in the Vegetative State', Science, 313 (2006), p. 1402. 
- D. Tarquini, M. Congedo, F. Formaglio, M. Gasparini, N. Marcello, C. Porteri, E. Pucci, S. Zullo, C.A. Defanti, 'Persistent Vegetative State: An Ethical Reappraisal', Journal of Neurological Sciences, Vol. 33, n. 3, 2012, pp. 695-700 (DOI 10.1007/s10072-011-0867-y). ISSN: 1590-1874

- C. Tripodina, Il diritto nell'età della tecnica: Il caso dell'eutanasia (Naples: Jovene, 2004).

- P: Veronesi, II corpo e la Costituzione: Concretezza dei "casi" e astrattezza della norma (Milan, Giuffré, 2007).

- J. Wilkinson, G. Kahane, M. Horne and J. Savulescu, 'Functional Neuroimaging and Withdrawal of Life-Sustaining Treatment from Vegetative Patients', Journal of Medical Ethics, 8 (2009), pp. 50811.

Fecha de recepción: 9 de octubre 2012

Fecha de aceptación: 19 de noviembre 2012 